\title{
DISFIGUREMENT, IN THREE PARTS
}

1

Sit in the close room. Roll up your shirtsleeve.

Your forearm is corded by blue veins. Eased

to the surface by another heavy August day, in this, your new city of subways and white noise.

II

Your arm has an abrupt topography. Lashes put down by a metal object. Something came and gave you a sign: mark yourself thus, and you'll again be able to eat in the company of others. Mark yourself and let your currency hemorrhage, let it pool in the strange basin. Swallow a cup of water. Wash yourself, walk.

III

Pass your fingertips over the scars. They are raised, parallel. Like the railroad sleepers in the backwoods of the back town, where tall trees in narrow silver suits let light perforate your ignorant face. Before cities. Before their incoherent premises, which echo and quake and cause the body to mutilate, then bloom. 


\section{DIVERGENCE}

It is Sunday, and parts of your body struggle. The curb atrophies into road, your jugular greens. Neon crucifixes plot jewelled coordinates, which you fail to follow. Silhouettes whom you may or may not know appear under plane trees, and stare. Signals report; you can not answer. Vehicles reel past. Your face gets disarranged, then rearranged, in their succession of anonymous glass.

It is Sunday, and parts of your body struggle to relate to other parts of other bodies. The streets smell like sterilised carcass. Red leaves vortex. You have become a friend to your acquaintances, and an acquaintance to your friends, whom you fail; as the defunct street lights fail the empty lots of light. As the sprawling vines, choking the row houses, fail to unwind 


\section{CULTURE, STRATA}

RALF WEBB

White rooms repeat themselves

Across the former warehouse districts

They proliferate as divisions proliferate

Are your devices in order, current

Is the line of your garment suitably clean

Can you suggest affluence by omission

White rooms contain singular audiences

And mutely occlude confluences:

The ecstatic intersections of the city exterior

Are you immaculately iced, impervious

Did you quit your hayseed accent

And cut your blemishes off, whet your jaw

Inside white rooms men repeat themselves

Via gross presence, via platforms

(That man is a fraud, as that man is a fraud)

Will you let them pillage your ethics

For pure transit, dazzling ingress

Out of the margins into aseptic white 